\title{
Akut Cryptosporidium İshalinin Nadir Bir Komplikasyonu: İmmün Yetmezlik Bulunmayan Çocuk Olguda Olası Hepatobiliyer Tutulum
}

\author{
A Rare Complication of Acute Diarrhae Caused by \\ Cryptosporidium: Possible Hepatobiliary System Involvement in \\ a Child without Immunodeficiency
}

\author{
Zeynep SAVAŞ ŞEN ${ }^{1}$, Medine Ayşin TAŞAR ${ }^{2}$, Filiz DEMiREL KAYA ${ }^{3}$, Abdullah GÜNEŞ ${ }^{1}$, \\ Emine VEZIR ${ }^{4}$, Hayriye HIZARCIOĞLU GÜLŞEN ${ }^{5}$ \\ 1 T.C. Sağlık Bakanlığı Sağlık Bilimleri Üniversitesi Ankara Eğitim ve Araştırma Hastanesi, Çocuk Sağlığı ve Hastalıkları \\ Bölümü, Ankara \\ ${ }^{1}$ Health Sciences University Ankara Training and Research Hospital, Department of Pediatrics, Ankara, Turkey. \\ 2 T.C. Sağlık Bakanlığı Sağlık Bilimleri Üniversitesi Ankara Eğitim ve Araştırma Hastanesi, Çocuk Sağlığı ve Hastalıkları \\ Bölümü, Çocuk Acil Kliniği, Ankara \\ ${ }^{2}$ Health Sciences University Ankara Training and Research Hospital, Department of Pediatrics, Clinic of Pediatric Emergency, \\ Ankara, Turkey. \\ 3 T.C. Sağlık Bakanlığı Sağlık Bilimleri Üniversitesi Ankara Eğitim ve Araştırma Hastanesi, Tıbbi Mikrobiyoloji Bölümü, \\ Parazitoloji Birimi, Ankara \\ ${ }^{3}$ Health Sciences University Ankara Training and Research Hospital, Department of Medical Microbiology, Division of \\ Parasitology, Ankara, Turkey. \\ ${ }^{4}$ T.C. Sağlık Bakanlığı Sağlık Bilimleri Üniversitesi Ankara Eğitim ve Araştırma Hastanesi, Çocuk Sağlığı ve Hastalıkları \\ Bölümü, Çocuk Allerji ve İmmünoloji Kliniği, Ankara. \\ ${ }^{4}$ Health Sciences University Ankara Training and Research Hospital, Department of Pediatrics, Clinic of Pediatric Allergy \\ and Immunology, Ankara, Turkey. \\ 5 T.C. Sağlık Bakanlığı Sağlık Bilimleri Üniversitesi Ankara Eğitim ve Araştırma Hastanesi, Çocuk Sağlığı ve Hastalıkları \\ Bölümü, Çocuk Gastroenteroloji Kliniği, Ankara. \\ ${ }^{5}$ Health Sciences University Ankara Training and Research Hospital, Department of Pediatrics, Clinic of Pediatric \\ Gastroenterology, Ankara, Turkey.
}

Makale Atıfı: Savaş Şen Z, Taşar MA, Demirel Kaya F, Güneş A, Vezir E, Hızarcıoğlu Gülşen H. Akut cryptosporidium ishalinin nadir bir komplikasyonu: immün yetmezlik bulunmayan çocuk olguda olası hepatobiliyer tutulum. Mikrobiyol Bul 2019;53(4):464-471.

ÖZ

Cryptosporidium spp., parazitik ishal nedenlerinin başında yer almaktadır. Giardia ile birlikte tüm dünyada insanlarda en sık görülen parazittir. İnsan immün yetmezlik virüsü (HIV)/kazanılmış immün yetmezlik sendromu (AIDS) tanısı olan hastalardaki kronik ishalin de önemli bir nedenidir. İmmün sistemi normal olan hastalarda asemptomatik seyir ya da akut kansız-sulu ishal ve persistan ishal gibi klinik tablolar görülebilir. Hastalığın şiddeti ve süresi bireyin immün yetersizliğinin bir yansıması olabilir. i̇ki yaş altı çocuklar ve malnütrisyonu olan çocuklarda immün yetmezlik tetkikleri normal olsa bile doğal immün 
sistem ve lenfosit fonksiyonlarında defekt olabileceği için uzamış Cryptosporidium spp. enfeksiyonu için risk olabilmektedir. Cryptosporidium spp. ookistleri klorlamaya kısmi dirençli olması nedeniyle su kaynakları, yüzme havuzları, sebze ve meyveleri kontamine ederek toplum sağlığı açısından risk oluşturmaktadır. Evcil hayvanlar, çiftlik hayvanları ve insanlar Cryptosporidium spp. taşıyıcısı olabilmektedir. Ülkelerin gelişmişlik düzeyleri, immün sistem, beslenme durumu, kalabalık ortamlarda yaşam, kontamine su ile temas, hayvanlarla yakın temas, hastanede çalışma ve sıcak ve nemli iklim gibi faktörler Cryptosporidium spp. görülme sıklı̆ını etkilemektedir. Cryptosporidium spp., 1-7 günlük inkübasyon periyodunu takiben asemptomatik bir enfeksiyona, hafif bir ishalli hastalığa veya bulantı, kusma, karın ağrısı ve bazen ateşin de eşlik edebileceği yüksek hacimli ciddi ishale neden olabilir. İshal, akut veya kronik, geçici, aralıklı veya sürekli olabilir; ciddi ishalde 25 L/gün'e kadar sıvı kaybı olabilmektedir. Cryptosporidium spp.'nin başııca yerleştiği yer bağırsaklar olmasına karşın, immün sistemi baskılanmış hastalarda bağırsak dışı (safra kanalları, pankreas, mide, solunum sistemi, böbrek) tutulumu da görülebilir. Hepatobiliyer sistem tutulumu AIDS'li hastaların \%10-30'unda görülür; taşsız kolesistit, sklerozan kolanjit ve pankreatite yol açabilir. İmmün yetmezliği olmayanlarda hepatobiliyer sistem tutulumu beklenmemektedir. Bu raporda, çocuk acil kliniğine ciddi ishal şikayeti ile başvuran ve dışkı örneğinin parazitolojik incelemesinde Cryptosporidium spp. ookistleri saptanan, özgeçmiş ve tetkikleri ile immün yetmezlik düşünülmeyen, izlemde hepatobiliyer sistem tutulumu görülen kriptosporidiyoz olgusu sunulmaktadır. Bu olgu ile Cryptosporidium spp. türlerinin, immün yetmezliği olmayan kişilerde de şiddetli akut ishal nedeni olabileceği ve ayrıca hepatobiliyer sistem tutulumu yapabileceği vurgulanmıştır.

Anahtar kelimeler: Cryptosporidium spp.; hepatobiliyer sistem; ishal; immün yetmezlik; çocuk.

\section{ABSTRACT}

Cryptosporidium spp. is one of the leading causes of parasitic diarrhea. It is the most common parasite in humans all over the world with Giardia. Cryptosporidium is an important cause of chronic diarrhea in Human Immunodeficiency Virus (HIV)/Acquired Immunodeficiency Syndrome (AIDS) patients. Patients with normal immune system may have an asymptomatic course or clinical presentation such as acute watery diarrhea without blood and persistent diarrhea. The severity and duration of the disease may be a reflection of the immune deficiency. Children under two years of age and children with malnutrition may have a risk of prolonged Cryptosporidium spp. infection, even if immunodeficiency work-up is normal, as they may have defects in the natural immune system and lymphocyte functions. Cryptosporidium spp. oocysts contaminate water sources, swimming pools, vegetables and fruits because oocysts are partially resistant to chlorination. So it may be problem for public health. Pets, livestock and humans can be carriers of Cryptosporidium spp. Factors such as developmental level of the countries, immune system, nutritional status, living in crowded environments, contact with contaminated water, close contact with animals, working at a hospital and hot and humid climate affect the incidence of Cryptosporidiosis. Cryptosporidium spp. may cause asymptomatic infection, mild diarrheal disease or severe diarrhea with high volume, which may be accompanied by nausea, vomiting, abdominal pain and fever, following a 1-7 day incubation period. Diarrhea may be acute or chronic, transient, intermittent, or continuous; loss of fluid can be up to $25 \mathrm{~L}$ /day in severe diarrhea. Cryptosporidium spp. are mainly located in intestines, but non-intestinal (bile ducts, pancreas, stomach, respiratory system, kidney) involvement may occur in immunocompromised patients. Hepatobiliary system involvement occurs in 10-30\% of patients with AIDS; stone-free cholecystitis can lead to sclerosing cholangitis and pancreatitis. Hepatobiliary involvement is not expected in patients without immunodeficiency. In this article, we present a case of Cryptosporodiosis with hepatobiliary system involvement who were admitted to the pediatric emergency clinic with the complaints of severe diarrhea and Cryptosporidium spp. oocysts were detected in parasitological examination of the stool specimen. Immunodeficiency was not considered with her resume and laboratuary examinations. We would like to emphasize that Cryptosporodium spp. may be the cause of severe acute diarrhea in non-immunocompromised patients and may also involve hepatobiliary system involvement.

Keywords: Cryptosporidium spp.; hepatobiliary system; diarrhea; immunodeficiency; child. 


\section{Gíriş}

Cryptosporidium spp. tüm vertebralı hayvanlarda gastrointestinal hastalıklara neden olabilen hücre içi bir protozoondur. Giardia ile birlikte tüm dünyada insanlarda en sık görülen parazittir ${ }^{1}$.

Cryptosporidium spp. türleri ookist oluşturan coccidian protozoa türüdür. Ookistler, enfekte konakçının dışkısı ile atıır ve fekal-oral yolla bulaşır ${ }^{2}$. Respiratuvar bulaş da bildirilmiştir ${ }^{3}$.

Kriptosporidiyoz enfeksiyonu bulgusuz olabileceği gibi, sıklıkla kansız, sulu ishale neden olur. Diğer bulgular, kramp şeklinde karın ağrısı, halsizlik, ateş, kusma, iştahsızlık ve kilo kaybıdır. Kriptosporidiyoz enfeksiyonuna sahip immün yetmezliği olmayan erişkin ve çocuklarda ishal genellikle 2-3 haftada kendini sınırlayıcı özelliğe sahiptir. İmmün sistemi baskılanmış kişilerde enfeksiyonun seyri kısa süreli ve hızlı iyileşme gösteren ishal şeklinde ya da yaşamı tehdit eden kolera benzeri ishal, malabsorpsiyon ve malnütrisyonla sonuçlanan kronik ishal şeklinde olabilir. Özellikle kazanıımıs immün yetmezlik sendromu (AIDS), kızamık gibi viral hastalıklarda, lösemi, gamaglobulinemiler, insüline bağımlı diyabet, böbrek yetmezliği, solid organ transplantasyonu ve kanser tedavisi gören hastalarda semptomlar şiddetlidir. Bu hastalarda ishal iki aydan uzun sürebilir, tüm enfeksiyon süresince dışkı ile ookist atıııı, şiddetli dehidratasyon, kilo kaybı ve malnütrisyon görülürr ${ }^{1,2}$.

Cryptosporidium spp.'nin başlıca yerleştiği yer bağırsaklar olmasına karşın, immün sistemi baskılanmış hastalarda bağırsak dışı (safra kanalları, pankreas, mide, solunum sistemi, böbrek) tutulum da görülebilir. Bu hastalarda bağırsak kanalından hematojen yayılımın gerçekleştiği düşünülmektedir ${ }^{1,4}$.

Hepatobiliyer sistem tutulumu hümoral ya da hücresel immün yetmezlikli hastalarda görülmektedir. AIDS'li hastaların \%10-30'unda bildirilmiş olup taşsız kolesistit, sklerozan kolanjit ve pankreatit kliniği ile seyreder ${ }^{5-7}$; fakat sağlıklı çocuklarda hepatobiliyer tutulum beklenmez.

Bu raporda çocuk acil kliniğine ciddi ishal şikayeti ile başvuran, immün yetmezlik bulguları olmayan ve dışkı örneğinin direkt muayenesinde Cryptosporodium spp. ookistleri saptanan bir olgu sunulmuştur. Bu olgu ile Cryptosporodium spp.'nin immün yetmezliği olmayan sağlıklı çocuklarda da şiddetli akut ishale ve hepatobiliyer sistem tutulumuna neden olabileceği vurgulanmıştır.

\section{OLGU SUNUMU}

Sekiz yaş altı aylık kız hasta, çocuk acil servisine iki gündür varolan ateş, sayısı günde 40'a varan çok sulu, sarı renkli, kan ve mukus içermeyen ishal ve günde 7-8 kez fışkııır tarzda kusma şikayeti ile başvurdu. Öyküsünde babasında da benzer şikayetlerin olduğu, ailenin evcil hayvanlarının olmadığı, hayvan temasının olmadığı, köy ziyaretinin olmadığı ifade edilmiştir. Hastanın özgeçmişi sorgulandığında daha önce ciddi bir enfeksiyon geçirmediği, herhangi bir enfeksiyon nedeni ile hastaneye yatışı olmadığı, kronik bir hastalığı olmadığı ve devamlı kullandığı bir ilaç olmadığı öğrenildi. Soygeçmişinde anne baba ara- 
sında akrabalık ve ailede immün yetmezlik öyküsü yoktu. Yapılan fizik muayenesinde vücut ısısı $38.9^{\circ} \mathrm{C}$, nabız 110/dakika, kan basıncı 82/56 mmHg bulundu. Vücut ağırlığı 25.5 kg (\%25-50) ve boy $130 \mathrm{~cm}$ (\%50) olarak saptandı. Genel durumu halsiz olan hastanın göz küreleri çökük, cilt turgorunda azalma, kapiler geri dolum zamanı $<2$ saniye olarak saptandı. Yapılan tetkiklerde üre $55 \mathrm{mg} / \mathrm{dl}$, kreatinin $0.47 \mathrm{mg} / \mathrm{dl}$, sodyum $145 \mathrm{mmol} / \mathrm{L}$, potasyum $4.2 \mathrm{mmol} / \mathrm{L}$, klor $95 \mathrm{mmol} / \mathrm{L}$, beyaz küre sayısı $7760 / \mathrm{mm}^{3}$, hemoglobin $14.8 \mathrm{~g} / \mathrm{dl}$, hematokrit \%43.4, trombosit sayısı 250.000/ $\mathrm{mm}^{3}$, C-reaktif protein (CRP) $6.27 \mathrm{mg} / \mathrm{L}$, aspartat aminotransferaz (AST) $34 \mathrm{U} / \mathrm{L}$, alanin aminotransferaz (ALT) $20 \mathrm{U} / \mathrm{L}$, eritrosit sedimentasyon hızı $2 \mathrm{~mm} / \mathrm{saat}$, kan gazında pH 7.42, bikarbonat $\left(\mathrm{HCO}_{3}\right) 22.2 \mathrm{mmol} / \mathrm{L}$ bulundu.

Hastadan alınan taze dışkı örneğinin nativ-lugol yöntemi ile yapılan direkt mikroskobik incelemesinde lökosit, eritrosit, parazit yumurtası, kist ya da trofozoite rastlanmadı. Konsantrasyon yöntemi sonrası elde edilen sedimentin lugol ile yapılan mikroskobik incelenmesi sırasında maya büyüklüğünde yuvarlak yapılar görüldü. Sedimentten hazırlanan yayma Kinyoun modifiye aside dirençli boyama yöntemi ile boyandı ve yapılan incelemede $\times 1000$ büyütmede 4-5 $\mu \mathrm{m}$ çapında, pembe-kırmızı boyanmış Cryptosporidium spp. ookistleri saptandı (Resim 1). İdrar, kan ve dışkı kültürlerinde patojen mikroorganizma üremesi olmadı.

Hastanın dışkısında Cryptosporidium spp. saptanması nedeniyle hasta immün yetmezlik açısından değerlendirildi. Nötropeni ve lenfopeni saptanmayan hastada insan immün yetmezlik virüsü antikoru (anti-HIV antikoru) negatif, lgG 715 mg/dl, lgA 77 mg/dl, lgM $129.4 \mathrm{mg} / \mathrm{dl}$, total lgE $27.86 \mathrm{IU} / \mathrm{ml}$, kompleman 3 (C3) $143.5 \mathrm{mg} / \mathrm{dl}, \mathrm{C} 428.4 \mathrm{mg} / \mathrm{dl}$ değerleri yaşa göre normal sınırlar içerisinde bulundu. Lenfosit alt grup analizi yüzde ve absolü sayıları yaşa göre normal olarak belirlendi. Hastada mevcut tablosu ile immün yetmezlik düşünülmedi. Hastanın izleminde başvurusundan bir hafta sonra bakılan kontrol dışkı örneğinde de Cryptosporidium spp. ookistleri mevcuttu.

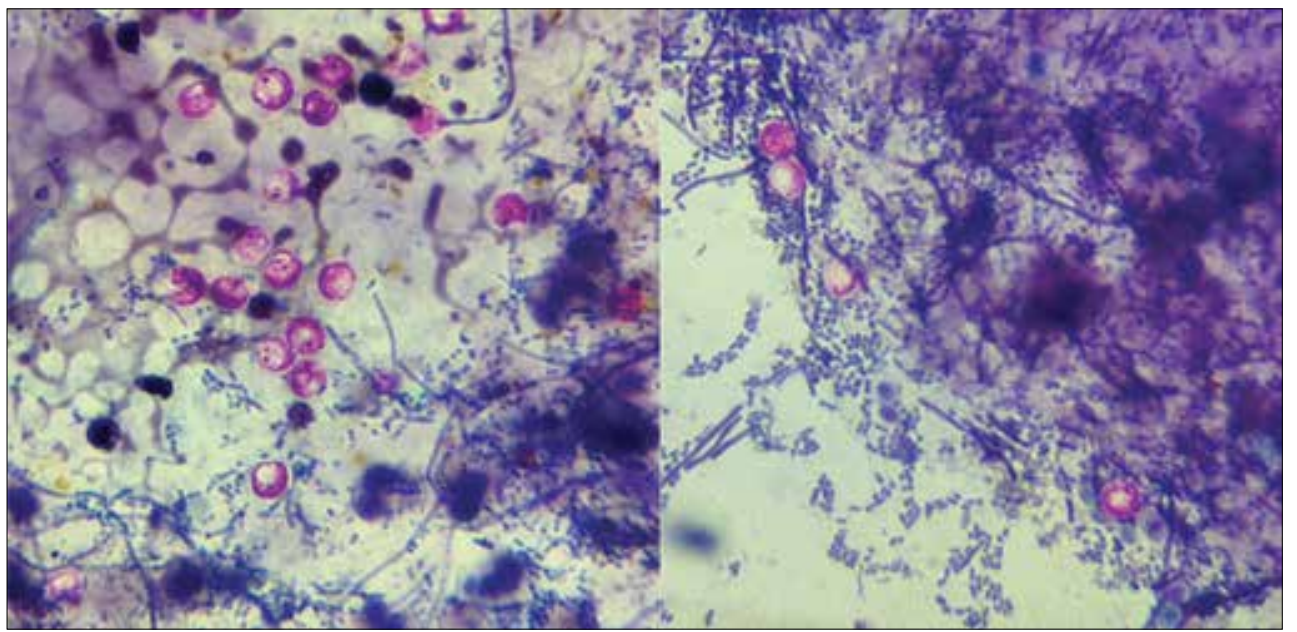

Resim 1. Dışkı örneğinde Cryptosporidium spp. ookistinin Modifiye Kinyoun'un aside dirençli boyama yöntemi ile görünümü. 
Akut gastroenterit ve orta derecede dehidratasyon tanısı ile yatırılan hastaya damar içi sıvı tedavisi verildi. Hasta dışkı sıklığının azalması, ağızdan sıvı alımının düzelmesi nedeniyle diyet önerileri ve $2 \times 10^{9} \mathrm{cfu} / 5 \mathrm{ml}$ Bacillus clausii içeren probiyotik tedavisi ile taburcu edildi.

Hasta ilk başvurusundan 15 gün sonra, karın ağrısı, ishal ve bulantı şikayetlerinin devam etmesi nedeniyle tekrar değerlendirildi. Fizik muayenesinde özellik saptanmadı. Laboratuvar testlerinde; AST $531 \mathrm{IU} / \mathrm{L}$, ALT 454 IU/L, gama glutamil transferaz (GGT) 81 IU/L, laktik dehidrogenaz (LDH) 367 IU/L değerleri saptanarak yüksek bulundu. Total bilirubin $0.39 \mathrm{mg} / \mathrm{dl}$, direkt bilirubin $0.12 \mathrm{mg} / \mathrm{dl}$, protrombin zamanı 14 saniye, aktif parsiyel tromboplastin zamanı 32.3 saniye, INR 1.1 değeri ile normal sınırlarda tespit edildi. Hastanın abdomen ve hepatobiliyer ultrasonografisinde safra kesesi lümeninde seviyelenme gösteren yoğunlaşmış safra çamuru saptandı. Dört gün sonra bakılan karaciğer fonksiyon testleri AST 26 IU/L, ALT 111 IU/L, GGT 63 IU/L şeklindeyken, 15 gün sonra bakılan ALT değeri $21 \mathrm{IU} / \mathrm{L}$, GGT $5 \mathrm{IU} / \mathrm{L}$ ile normal sınırlarda saptandı. Karaciğer fonksiyon testleri yüksekliği nedeni ile bakılan anti-HAV IgM, anti-HCV, HBs antijeni, anti-rubella IgM, anti-CMV IgM, anti-EBV VCA IgM, anti-endomisyum IgA, anti-doku transglutaminaz lgA ve IgG, anti-nükleer antikor, anti-ds DNA, anti-mitokondriyal antikor, anti-liver kidney mikrozomal antikor ve anti-düz kas antikorları negatif olarak bulundu. Hastanın bu başvurusunda T.C. Halk Sağlığı Genel Müdürlüğüne gönderilen dışkı örneğinin polimeraz zincir reaksiyonu (PCR) ile incelenmesinde Cryptosporidium spp. pozitif olarak sonuçlandı. Son kontrolde bakılan AST $16 \mathrm{IU} / \mathrm{L}$, ALT $12 \mathrm{IU} / \mathrm{L}$, GGT $6 \mathrm{IU} / \mathrm{L}$, direkt bilirubin $0.13 \mathrm{mg} / \mathrm{dl}$, indirekt bilirubin $0.3 \mathrm{mg} / \mathrm{dl}$ ile normal sınırlarda olan hastanın izleminde ateşi bir hafta, kusma şikayeti aralıklı olarak iki hafta ve ishal tablosu yaklaşık bir ay devam etti. Uzamış ishal ve eşlik eden hepatit nedeniyle inflamatuvar bağırsak hastalığı şüphesi ile yapılan kolonoskopisi normal sınırlardaydı.

\section{TARTIŞMA}

Cryptosporidium spp. enfestasyonları iki yaş altı çocuklarda, yaşlılarda ve immün yetmezliği olan kişilerde hayatı tehdit eden ciddi gastroenterit tablosuna neden olabilmektedir $^{1,2,8}$.Parazitin klorlamaya kısmi dirençli oluşu su kaynaklı bulaş ihtimalini artırmakta olup, Dünya Sağlık Örgütü su kalitesi açısından referans patojen olarak Cryptosporidium spp.'yi belirlemiştir ${ }^{3}$. Olgumuzun babasında da benzer şikayetlerin olması ailenin yaşadığı bölgede su kaynaklarının veya yiyeceklerin Cryptosporidium spp. ile kontamine olma olasılığının bulunduğunu düşündürmektedir.

Kriptosporidiyoz, gelişmiş ülkelerde immün sistemi sağlam olan kişilerde \%1-3-9 sıklığında, gelişmekte olan ülkelerde \%7-10-20 sıklığında bildirilmektedir ${ }^{3,4,7,9}$. Ülkemizden Van ve İzmir'de akut ishal şikayeti ile başvuran çocuklarda yapılan çalışmalarda dışkı örneklerinde Cryptosporidium spp. ookisti varlığı \%2.2 ve \%13.5 sıklığında bildirilmiştir ${ }^{10,11}$.

Cryptosporidium spp. ishali, akut veya kronik, geçici, aralıklı veya sürekli olabilir; ciddi ishalde 25 L/gün'e kadar sıvı kaybı olabilirr ${ }^{1,2}$. Olgumuzda, literatüre benzer şekilde, baş- 
langıçta sayısı günde 40'a varan çok sulu, sarı renkli, kan ve mukus içermeyen, yaklaşık bir ay süren ishal mevcuttu.

Kriptosporidiyoza immün yanıt, doğal ve edinsel immün sistem yolakları ile olmaktadır. Hücre içi bir parazit olması nedeniyle edinsel immün yanıtta hücre aracılı immün yanıtlar özellikle CD4+ T lenfositler ve IFN- $\gamma$ rol almaktadır. Bu yolaklarda sorun oluşturan primer ve sekonder immün yetmezlikler (HIV enfeksiyonu, $X^{\prime}$ e bağlı hiperimmünglobulin M- CD40 Ligand eksikliği, kombine immün yetmezlik, T hücre eksiklikleri, organ transplantasyonu, akut lösemi, IgA eksikliği, hipogammaglobulinemi, immün baskılayıcı tedavi) uzamış enfeksiyon için risk faktörleridir ${ }^{1}$. İki yaş altı çocuklar ve malnütrisyonu olan çocuklarda immün yetmezlik tetkikleri normal olsa bile doğal immün sistem ve lenfosit fonksiyonlarında defekt olabileceği için uzamış Cryptosporidium spp. enfeksiyonu için risk olabilmektedir. Hastamızın 8.5 yaşında olması, öncesinde enfeksiyon öyküsünün olmaması, büyüme ve gelişmesinin normal olması, tam kan sayımı, immünglobulinler, lenfosit alt grup analizi sonuçlarının normal olması, anti-HIV antikorunun negatif olması nedeniyle primer ve sekonder immün yetmezlik düşünülmemiştir.

2017'de yayımlanan bir meta-analizde çocuklarda özellikle uzamış ishalde Cryptosporidium spp. prevalansının daha yüksek olduğu ve HIV pozitifliği ile uzamış ishalin ilişkili olduğu bildirilmiştir ${ }^{8}$. Olgumuzdan alınan öyküden daha önce ciddi bir enfeksiyon geçirmediği, herhangi bir enfeksiyon nedeniyle hastaneye yatışı olmadığı, kronik bir hastalığı olmadığı ve devamlı kullandığı bir ilaç olmadığı öğrenildi. Risk faktörleri olarak malnütrisyonu ve bilinen bir immün yetmezliği olmadığı belirlendi.

İmmün sistemi baskılanmış hastalarda Cryptosporidium spp. ile bağırsak dışı (safra kanalları, pankreas, mide, solunum sistemi, böbrek) organ tutulumu bildirilmiştir ${ }^{1,4}$. Sistematik tarama yapıldığında primer immün yetmezliklerden özellikle hiperimmünglobulin M sendromlu hastalarda \%70'e varan oranda Cryptosporidium spp. kolonizasyonu olduğu ve bunun sklerozan kolanjit başta olmak üzere hepatitten son dönem karaciğer hastalığına kadar uzanan ciddi sorunlara yol açtığı bildirilmiştir ${ }^{12}$. Sekonder immün yetmezliklerden AIDS tanısı olan hastaların \%10-30'unda biliyer sistem tutulum görülebileceği; taşsız kolesistit, sklerozan kolanjit ve pankreatit şeklinde ortaya çıkabileceği bildirilmiştir $6,13,14$.

Cryptosporidium spp.'nin, bağırsak lümeni yoluyla, üreme sistemine ve hepatobiliyer sisteme yayılabileceği ve bu yolla kolesistit, pankreatit ve daha özgül olarak sklerozan kolanjit ve kolanjiyokarsinoma yol açabileceği bildirilmektedir ${ }^{1}$. Biliyer hasara parazitin apopitoz ilişkili direkt sitopatik etkisinin neden olduğu düşünülmektedir ${ }^{15}$. Biliyer hasarın etyolojisine yönelik hayvanlarda yapılmış olan çalışmada kolanjit hasarına tümör nekroz faktörünün (TNF) katkıda bulunduğu, başka bir çalışmada ise CD40 ve CD40L ilişkisinin Cryptosporidium spp. eradikasyonunda gerekli olduğu gösterilmiştir ${ }^{16,17}$. Yapılan başka bir hayvan deneyinde, Cryptosporidium parvum enfeksiyonunun in vivo etkili eradikasyonu için TLR4 aracılı yanıtın gerekli olduğu ve bu olaya ait tanıma reseptörünün yokluğunun, değişmiş bir inflamatuvar yanıta ve hepatobiliyer patolojide artışa katkıda bulunduğu saptanmıştır ${ }^{18}$. 
İmmün sistem bozukluğu olmayan bireylerde safra yolları tutulumu beklenmemektedir. Literatürde sadece primer immünolojik tetkikleri ve özgeçmişi doğrultusunda bilinen immün yetmezliği olmadığı düşünülen ve Cryptosporidium spp. enfeksiyonu ilişkili dirençli ishal ve sklerozan kolanjiti olan bir çocuk hasta bildirilmiştir ${ }^{19}$. Bizim hastamızın kliniğinin kronik karaciğer hasarı ile uyumlu olmadığı ve immün sistem fonksiyonları normal olduğu için kolanjiyosit hasarının sınırlanabildiği düşünüldü.

Sonuç olarak, bu raporda Cryptosporidium spp. türlerinin, immün yetmezliği olmayan kişilerde de şiddetli akut ishal nedeni olabileceği ve ayrıca geçici hepatobiliyer hasar yapabileceği vurgulanmıştır.

\section{ÇIKAR ÇATIŞMASI}

Yazarlar bu makale ile ilgili herhangi bir çıkar çatışması bildirmemişlerdir.

\section{KAYNAKLAR}

1. Leder K, Weller PF. Epidemiology, clinical manifestations, and diagnosis of cryptosporidiosis. Available from:URL:https://www.uptodate.com/contents/epidemiology-clinical-manifestations-and-diagnosis-ofcryptosporidiosis.

2. Cryptosporidium, pp: 312-5. In: Kimberlin DW, Brady MT, Jackson MA, Long SS, eds. Red Book: 2015 Report of the Committee on Infectious Diseases. 2015, 30 ${ }^{\text {th }}$ ed. Elk Grove Village, IL: American Academy of Pediatrics.

3. Bensen R, Fuentebella J, Fridge JL, Bass DM. Enteric parasites, pp: 463-77. In: Wyllie R, Hyams JS, Kay M (eds), Pediatric Gastroenterolgy and Liver Disease. 2016, $5^{\text {th }}$ ed. Philadelphia: Elsevier Inc.

4. Current WL, Garcia LS. Cryptosporidiosis. Clin Microbiol Rev 1991;4(3):325-58.

5. Verdon R, Keusch GT, Tzipori S, Grubman SA, Jefferson DM, Ward HD. An in vitro model of infection oh human biliary epithelial cells by Cryptosporidium parvum. J Infect Dis 1997;175(5):1268-72.

6. Günthard M, Meister T, Lüthy R. Weber R. Intestinal cryptosporidiosis in HIV infection: clinical features, course and therapy. Dtsch Med Wochenschr 1996;121(21):686-92.

7. Kuhls TL, Mosier DA, Crawford DL, Griffis J. Seroprevalence of cryptosporodial antibodies during infancy, childhood and adolescence. Clin Infect Dis 1994;18(5):731-5.

8. Dabas A, Shah D, Bhatnagar S, Lodha R. Epidemiology of Cryptosporidium in pediatric diarrheal illnesses. Indian Pediatrics 2017;54(4):299-309.

9. Casemore DP. Epidemiological aspects of human cryptosporidiosis. Epidemiol Infect 1990;104(1):1-28.

10. Çiçek M, Yılmaz H. İshalli çocuklarda Cryptosporidium spp. ve diğer barsak parazitlerinin yaygınlığı. Dicle Tıp Dergisi 2011;38(1):70-5.

11. Koturoğlu G, Bayram S, Kurugöl Z, Turgay N, Mutlubaş F. Akut ishalli çocuklarda Cryptosporodium sıklığı ve risk faktörleri. Türkiye Klinikleri J Pediatr 2004;13(1):16-9.

12. Rodrigues F, Davies EG, Harrison P, McLauchlin J, Karani J, Portmann B, et al. Liver disease in children with primary immunodeficiencies. J Pediatr 2004;145(3):333-9.

13. Gross TL, Wheat J, Barlett M, O'Connor KW. AIDS and multiple system involvement with Cryptosporidium. Am J Gastroenterol 1986;81(1):456-8.

14. Vakil NB, Schwartz SM, Buggy BP, Brummitt CF, Kherellah M, Letzer DM, et al. Biliary cryptosporidiosis in HIV-infected people after the waterborne outbreak of cryptosporidiosis in Milwaukee German. N Engl J Med 1996;334(1):19-23.

15. Hadžić N, Ball C. Immune deficiency and the liver, pp: 3421-64. In: Kleinman RE, Goulet OJ, Mieli-Vergani G, Sanderson IR, Sherman PM, Shneider BL (eds), Walker's Pediatric Gastrointestinal Disease; Pathophysiology, Diagnosis, Management. 2018, $6^{\text {th }}$ ed. Raleigh: People's Medical Publishing House-USA. 
16. Ponnuraj EM, Hayward AR. Requirement for TNF Tnfrsf1 signalling for sclerosing cholangitis in micechronically infected by Cryptosporidium parvum. Clin Exp Immunol 2002;128(3):416-20.

17. Cosyns M, Tsirkin S, Jones M, Flavell R, Kikutani H, Hayward AR. Requirement of CD40-CD40 ligand interaction for elimination of Cryptosporidium parvum from mice. Infect Immun 1998;66(2):603-7.

18. Borad A, Ward H. Human immune reponses in cryptosporidiosis. Future Microbiol 2010;5:507-19.

19. Goddard EA, Mouton SC, Westwood AT, Ireland JD, Durra G. Cryptosporidiosis of the gastrointestinal tract associated with sclerosing cholangitis in the absence of documented immunodeficiency: Cryptosporidium parvum and sclerosing cholangitis in an immunocompetent child. J Pediatr Gastroenterol Nutr 2000;31(3):31720. 